\title{
Pengaruh Kualitas Produk dan Harga Terhadap Keputusan Pembelian Sayur Organik di "Orgo Organic Farm" Kota Malang
}

\section{The Effect of Product Quality and Price on the Decision to Purchase Organic Vegetables at "Orgo Organic Farm" Malang City}

\author{
Shania Desty Hariadi ${ }^{1}$, Rahayu Relawati ${ }^{1 *}$, Istis Baroh ${ }^{1}$ \\ ${ }^{1}$ Program Studi Agribisnis, Fakultas Pertanian-Peternakan, Universitas \\ Muhammadiyah Malang \\ Jl. Raya Tlogomas 246 Malang Gedung GKB 1 Lantai 5 \\ Email korespondensi: *rahayurelawati@umm.ac.id
}

Diterima tanggal : 24 Desember 2021 ; Disetujui tanggal : 30 Desember 2021

\begin{abstract}
"Orgo Organic Farm" conducts organic vegetable business from cultivation to marketing. The tight competition in the organic vegetable business in Malang requires business people to understand the factors that drive consumer decisions to make purchases. This study aims to analyze the effect of product quality and price on purchasing decisions at OOF. Primary data was obtained by interviewing OOF customers. Accidental sampling technique was used to determine the sample of OOF customers. Data were analyzed by Partial Least Square (PLS) method. The results showed that product quality and price had an effect on purchasing decisions at OOF. The conclusion of this study is that product quality has a positive and significant effect on consumer decisions with a $p$ value of 0,001 or less than 0,05. The original sample value (path coefficient) of 0,336 indicates the direction of a positive relationship and there is an influence of price on consumer decisions. Price is not significant to consumer decisions with a $p$ value of 0,109 or greater than 0,05. The original sample value (path coefficient) of 0,172 indicates the direction of a positive relationship.
\end{abstract}

Keywords: Organic Vegetables, Purchasing Decisions, Vegetable Prices, Vegetable Quality.

\begin{abstract}
ABSTRAK
"Orgo Organic Farm" melakukan bisnis sayur organik mulai dari budidaya hingga pemasaran. Ketatnya persaingan bisnis sayur organik di Malang mengharuskan pelaku bisnis memahami faktor-faktor yang mendorong keputusan konsumen melakukan pembelian. Penelitian ini bertujuan untuk menganalisis pengaruh kualitas produk dan harga terhadap keputusan pembelian di OOF. Data primer diperoleh dengan wawancara pelanggan OOF. Teknik accidental sampling digunakan untuk menentukan sampel pelanggan OOF. Data dianalisis dengan metode Partial Least Square (PLS). Hasil penelitian menunjukkan kualitas
\end{abstract}


produk dan harga berpengaruh terhadap keputusan pembelian di OOF. Kesimpulan penelitian ini yaitu kualitas produk berpengaruh positif dan signifikan terhadap keputusan konsumen dengan nilai $p$ value 0,001 atau lebih kecil dari 0,05. Nilai original sample (path coefficient) 0,336 menunjukkan arah hubungan positif dan terdapat pengaruh harga terhadap keputusan konsumen. Harga tidak signifikan terhadap keputusan konsumen dengan nilai $p$ value 0,109 atau lebih besar dari 0,05. Nilai original sampel (path coefficient) 0,172 menunjukan arah hubungan positif.

Kata kunci : Harga Sayur, Keputusan Pembelian, Kualitas Sayur, Sayur Organik.

\section{PENDAHULUAN}

Sayuran sangat dibutuhkan untuk kesehatan karena dengan tubuh yang sehat kita dapat melakukan segala aktivitas untuk memenuhi kebutuhan sehari-hari (Tafajani, 2011). Kendala bisnis sayur organik yaitu terbatasnya pembeli pada lapisan masyarakat tertentu dan sulitnya mendapatkan pelanggan di pasar tradisional, karena harga sayur organik yang lebih mahal dibanding sayur non organik (Putra et al., 2015). “Orgo Organic Farm” (selanjutnya disebut OOF) merupakan salah satu bisnis yang tetap konsisten melakukan budidaya tanaman hortikultura yang berbasis organik. OOF berlokasi di Kota Malang.

Penelitian terdahulu mengenai pengaruh kualitas produk dan harga terhadap keputusan pembelian (Pristiana, 2018; Sunarto, 2015; Habibah \& Sumiati, 2016; Harahap \& Hidayat, 2018) menghasilkan bahwa terdapat pengaruh kualitas produk dan harga terhadap keputusan pembelian. Penelitian terdahulu mengenai keputusan pembelian terhadap kualitas pelayanan, kualitas produk, harga dan variabel lain (Maaniya, Rois, Hufron, 2019; Cristo et al., 2017; Pertiwi et al., 2016; Pratiwi \& Yasa, 2019; Kim \& Lee, 2017) menghasilkan bahwa terdapat pengaruh kualitas pelayanan, kualitas produk, harga dan variabel lain dengan keputusan pembelian. Penelitian terdahulu mengenai keputusan pembelian terhadap kualitas produk (Davin \& Metta, 2016) menghasilkan bahwa terdapat pengaruh kualitas produk dengan keputusan pembelian.

Berbagai penelitian terdahulu belum mengkaji beberapa aspek indikator variabel yang dinilai berbeda dan belum diuji dengan penelitian terdahulu. Aspek 
indikator variabel tersebut dinilai penting bagi konsumen dalam melakukan keputusan pembelian. Kebaruan penelitian ini adalah terdapat pada aspek indikator variabel yang belum diuji dengan penelitian terdahulu. Berdasarkan latar belakang permasalahan di atas, penting untuk diketahui faktor-faktor apa saja yang mempengaruhi keputusan konsumen dalam melakukan pembelian di OOF Malang. Tujuan penelitian adalah menganalisis pengaruh kualitas produk terhadap keputusan pembelian di OOF dan menganalisis pengaruh harga terhadap keputusan pembelian di OOF.

\section{METODE PENELITIAN}

Pendekatan yang digunakan dalam penelitian ini adalah deskriptif kuantitatif. Data primer diperoleh dari konsumen OOF, melalui wawancara terstruktur dengan menggunakan kuesioner sebagai salah satu alat penggali data (Devi, 2019). Penelitian ini merupakan kategori penelitian asosiatif, yakni mencari pengaruh sebab akibat dari variabel bebas terhadap variabel terikat. Variabel bebas penelitian ini adalah kualitas produk (X1) dan harga (X2), sedangkan variabel terikatnya adalah keputuan pembelian (Y).

Pengambilan data primer dilaksanakan mulai bulan Juni sampai Agustus 2021. Penelitian ini dilakukan di gerai OOF yang berlokasi di Kota Malang. Teknik pengambilan sampel yang digunakan adalah accidental sampling, yakni teknik pengambilan sampel secara kebetulan (Sugiyono, 2007). Sampel yang dipilih adalah orang yang sedang berkunjung di OOF. Penentuan jumlah sampel yang representative adalah tergantung pada jumlah indikator dikali 5 sampai 10 .

Metode analisis data yang digunakan yaitu Partial Least Square (PLS), merupakan metode statistik yang menganalisis hubungan antara variabel laten yang diukur melalui indikator pengukuran (konstruk). PLS merupakan metode analisis yang powerfull karena dapat diterapkan pada semua skala data, tidak banyak membutuhkan asumsi, dan ukuran sampel tidak harus besar (Wiyono, 2011). Langkah-langkah analisis dengan menggunakan PLS sebagai berikut : 


\section{a. Model Pengukuran (Outer Model)}

Outer Model atau model pengukuran merupakan bentuk spesifikasi hubungan antara variabel laten dengan indikatornya. Jadi outer model atau model pengukuran ini mendefinisikan bagaimana setiap indikator dapat terhubung dengan variabel latennya.

\section{b. Model Struktural (Inner Model)}

Inner Model atau model struktural merupakan spesifikasi hubungan antar variabel laten (structural model). Inner model atau model struktural disebut juga dengan inner relation. Inner model atau model struktural menunjukkan hubungan antar variabel laten berdasarkan substantive theory dari penelitian.

Validitas konvergen terjadi jika skor yang diperoleh dari dua instrumen yang berberda yang mengukur konstruk yang sama mempunyai korelasi tinggi. Rule of thumb biasanya digunakan untuk membuat pemerikasaan awal dari matrik faktor. Dengan demikian, semakin tinggi nilai faktor loading, semakin penting peranan loading dalam mengintepretasi matrik faktor. Validitas diskriminan terjadi jika dua instrumen yang berbeda yang mengukur dua konstruk diprediksi tidak berkorelasi. Menghasilkan skor yang memang tidak berkorelasi. Model mempunyai validitas diskriminan yang cukup jika akar AVE untuk setiap konstruk lebih besar dari pada korelasi antara konstruk lainnya dalam model.

Uji reliabilitas adalah alat untuk mengukur konsistensi internal alat ukur yang memperhatikan keakuratan suatu alat ukur. Uji reliabilitas dalam PLS dapat menggunakan dua metode, yaitu metode Cronbach's alpha dan Composite reliability. Crombach's alpha mengukur batas bawah nilai reliabilitas suatu konstruk, sedangkan composite reliability mengukur nilai sesungguhnya reliabilitas suatu konstruk.

c. Pengujian Hipotesis 
Pengujian hipotesis penelitian ini dilakukan untuk mengetahui pengaruh variabel kualitas produk (X1), harga (X2), terhadap keputusan pembelian (Y). PLS yang digunakan pengambilan keputusan berdasarkan $p$-values.

1) P-values $\geq 0,05$ maka Ho diterima dan Ha ditolak.

2) P-values < 0,05 maka Ho ditolak dan Ha diterima.

\section{HASIL DAN PEMBAHASAN}

\section{Karakteristik Responden}

Karakteristik responden penting disajikan untuk memberi gambaran konsumen yang melakukan pembelian sayur organik di OOF. Karakteristik responden yang disajikan meliputi karakteristik responden berdasarkan usia, berdasarkan jenis kelamin, berdasarkan pekerjaan, berdasarkan pendapatan, berdasarkan frekuensi pembelian.

Tabel 1. Karakteristik Responden Berdasarkan Usia dan Jenis Kelamin

\begin{tabular}{lcc}
\hline Kriteria & Jumlah (Orang) & Persentase \\
\hline$<18$ tahun & 0 & $0 \%$ \\
$18-28$ tahun & 12 & $16 \%$ \\
$29-38$ tahun & 21 & $28 \%$ \\
$39-48$ tahun & 23 & $30,7 \%$ \\
$>48$ tahun & 19 & $25,3 \%$ \\
\hline Total & $\mathbf{7 5}$ & $\mathbf{1 0 0 \%}$ \\
\hline Jenis Kelamin & Jumlah (Orang) & Persentase \\
\hline Laki-laki & 15 & $20 \%$ \\
Perempuan & 60 & $80 \%$ \\
\hline Total & $\mathbf{7 5}$ & $\mathbf{1 0 0 \%}$
\end{tabular}

Sumber: Data Primer (2021)

Berdasarkan tabel 1 yaitu karakteristik responden berdasarkan usia. Diketahui jumlah responden terbanyak yaitu pada usia 39 sampai 48 tahun sebanyak 23 orang atau 30,7\% dari keseluruhan responden. Proporsi terendah yaitu pada usia 18 sampai 28 tahun sebanyak 12 orang atau $16 \%$ dari keseluruhan responden. Berdasarkan tabel 1 pada bagian karakteristik responden berdasarkan jenis kelamin. Diketahui jumlah responden laki-laki sebanyak 15 orang atau $20 \%$. Responden jenis kelamin perempuan sebanyak 60 orang atau $80 \%$. 
Tabel 2. Karakteristik Responden Berdasarkan Pekerjaan

\begin{tabular}{lcc}
\hline Kriteria & Jumlah (Orang) & Persentase \\
\hline Pegawai Negeri & 8 & $10,7 \%$ \\
Pegawai Swasta & 12 & $16 \%$ \\
Pegawai Honorer & 9 & $12 \%$ \\
Wirausaha & 25 & $33,3 \%$ \\
Ibu Rumah Tangga & 6 & $8 \%$ \\
Guru atau Dosen & 5 & $6,7 \%$ \\
Pelajar atau Mahasiswa & 8 & $10,7 \%$ \\
Pensiunan & 2 & $2,7 \%$ \\
\hline \multicolumn{1}{c}{ Total } & $\mathbf{7 5}$ & $\mathbf{1 0 0 \%}$
\end{tabular}

Sumber: Data Primer (2021)

Berdasarkan tabel 2 yaitu tabel karakteristik responden berdasarkan pekerjaan. Diketahui responden terbanyak dengan pekerjaan sebagai wirausaha sebanyak 25 orang atau 33,3\%. Responden terrendah dengan pekerjaan sebagai pensiunan sebanyak 2 orang atau $2,7 \%$ dari keseluruhan responden.

Tabel 3. Karakteristik Responden Berdasarkan Pendapatan dan Frekuensi Pembelian

\begin{tabular}{lcc}
\hline Pendapatan & Jumlah (Orang) & Persentase \\
\hline$<$ Rp 1.000.000 & 3 & $4 \%$ \\
Rp 1.000,000 - Rp 2.999.999 & 30 & $40 \%$ \\
Rp 3.000,000 - Rp 5.999.999 & 28 & $50,7 \%$ \\
Rp 6.000,000 - Rp 8.999.999 & 3 & $4 \%$ \\
$\geq$ Rp 9.000,000 & 1 & $1,3 \%$ \\
\hline Total & $\mathbf{7 5}$ & $\mathbf{1 0 0 \%}$ \\
\hline Frekuensi Pembelian & Jumlah (Orang) & Persentase \\
\hline Satu Kali & 22 & $29,3 \%$ \\
\hline Satu Kali & 53 & $70,7 \%$ \\
\hline Total & $\mathbf{7 5}$ & $\mathbf{1 0 0 \%}$ \\
\hline
\end{tabular}

Sumber: Data Primer (2021)

Berdasarkan tabel 3 yaitu tabel karakteristik responden berdasarkan penghasilan. Diketahui responden terbanyak berpenghasilan $\mathrm{Rp} 1.000 .000$ 
sampai Rp 2.999.999 sebanyak 30 orang atau 40\% dari total keseluruhan responden. Responden terendah penghasilan $\mathrm{Rp} 9.000 .000$ sebanyak 1 orang atau 1,3\% dari total responden. Berdasarkan tabel 3 yaitu bagian karakteristik responden berdasarkan frekuensi pembelian. Diketahui jumlah responden yang baru 1 kali membeli di OOF sebanyak 22 orang atau 29,3\%. Responden yang sudah melakukan pembelian di OOF lebih dari 1 kali sebanyak 53 orang atau $70,7 \%$.

\section{Pengujian Hipotesis Penelitian}

\section{Uji Validitas}

Convergent validity adalah evaluasi yang dilakukan pada masing-masing indikator terhadap konstruk. Indikator dianggap valid jika memiliki nilai korelasi diatas 0,70 . Hasil outer loading adalah sebagai berikut :

Tabel 4 Outer Loading

\begin{tabular}{llll}
\hline & X1 & X2 & Y \\
\hline X1.1 & 0,788 & & \\
X1.2 & 0,846 & & \\
X1.3 & 0,798 & & \\
X1.4 & 0,767 & & \\
X1.5 & 0,706 & 0,821 & \\
X2.1 & & 0,783 & \\
X2.2 & & 0,872 & \\
X2.3 & 0,792 & \\
X2.4 & 0,745 & \\
X2.5 & & \\
Y1.1 & & 0,761 \\
Y1.2 & & & 0,797 \\
Y1.3 & & 0,828 \\
Y1.4 & & & 0,736 \\
Y1.5 & & & \\
\hline
\end{tabular}

Sumber: Data Primer (2021)

Berdasarkan tabel 4 yaitu tabel loading factor diatas hasilnya telah memenuhi convergent validity karena loading factor diatas 0,70. Hal tersebut menunjukkan bahwa indikator valid. Dianggap tidak valid jika memiliki nilai korelasi dibawah 0,70 . Sehingga berdasarkan tabel loading factor ini maka dapat dilanjutkan pada tahapan analisis berikutnya.

\section{Uji Validitas Diskriminan}


Discriminant validity dapat dilihat pada cross loading antara indikator dengan konstruknya. Jika korelasi konstruk dengan item pengukuran lebih dari pada ukuran konstruk lainnya, maka akan menunjukkan bahwa konstruk laten memprediksi ukuran pada blok yang lebih baik dari pada ukuran blok lainnya. Hasil output cross loading adalah sebagai berikut :

Tabel 5 Cross Loading

\begin{tabular}{cccc}
\hline & $\mathbf{X 1}$ & $\mathbf{X 2}$ & $\mathbf{X 3}$ \\
\hline X1.1 & 0,788 & 0,163 & 0,335 \\
X1.2 & 0,846 & 0,273 & 0,350 \\
X1.3 & 0,798 & 0,313 & 0,347 \\
X1.4 & 0,767 & 0,242 & 0,253 \\
X1.5 & 0,706 & 0,158 & 0,133 \\
X2.1 & 0,234 & 0,821 & 0,211 \\
X2.2 & 0,194 & 0,783 & 0,125 \\
X2.3 & 0,290 & 0,872 & 0,338 \\
X2.4 & 0,261 & 0,792 & 0,141 \\
X2.5 & 0,201 & 0,745 & 0,137 \\
Y1.1 & 0,266 & 0,314 & 0,761 \\
Y1.2 & 0,368 & 0,259 & 0,833 \\
Y1.3 & 0,240 & 0,191 & 0,797 \\
Y1.4 & 0,314 & 0,166 & 0,828 \\
Y1.5 & 0,327 & 0,132 & 0,736 \\
\hline
\end{tabular}

Sumber: Data Primer (2021)

Diketahui bahwa nilai loading factor untuk setiap indikator dari masingmasing variabel laten memiliki nilai loading factor yang lebih besar dibandingkan nilai loading jika dihubungkan dengan variabel laten lainnya. Hal ini menunjukkan bahwa setiap variabel laten telah memiliki discriminant validity yang baik dimana variabel laten memiliki pengukur yang berkorelasi tinggi dengan konstruk lain atau validitas diskriminan di tingkat indikator terpenuhi.

Berdasarkan tabel 6 yaitu tabel outer loading (P-Value). Kesimpulan dari hasil pengujian validitas menggunakan construct validity, discriminant validity dan boostrapping loading (P-Value). Jika terdapat indikator yang tidak valid, maka indikator tersebut harus dikeluarkan dari loading factor dan dihitung kembali. 
Hariadi, et.al., Pengaruh Kualitas Produk dan Harga Terhadap Keputusan

Tabel 6. Outer Loading ( $P$-Value)

\begin{tabular}{lccccc}
\hline & $\begin{array}{c}\text { Sampel } \\
\text { Asli }\end{array}$ & $\begin{array}{c}\text { Sampel } \\
\text { Mean }\end{array}$ & $\begin{array}{c}\text { Standar } \\
\text { Deviasi }\end{array}$ & T Statistik & P Value \\
\hline $\mathrm{X} 1.1<-\mathrm{X} 1$ & 0,788 & 0,780 & 0,068 & 11,535 & 0,000 \\
$\mathrm{X} 1.2<-\mathrm{X} 1$ & 0,846 & 0,842 & 0,053 & 16,074 & 0,000 \\
$\mathrm{X} 1.3<-\mathrm{X} 1$ & 0,798 & 0,785 & 0,080 & 9,920 & 0,000 \\
$\mathrm{X} 1.4<-\mathrm{X} 1$ & 0,767 & 0,744 & 0,130 & 5,887 & 0,000 \\
$\mathrm{X} 1.5<-\mathrm{X} 1$ & 0,706 & 0,673 & 0,158 & 4,467 & 0,000 \\
$\mathrm{X} 2.1<-\mathrm{X} 2$ & 0,821 & 0,781 & 0,174 & 4,705 & 0,000 \\
$\mathrm{X} 2.2<-\mathrm{X} 2$ & 0,783 & 0,731 & 0,192 & 4,071 & 0,000 \\
$\mathrm{X} 2.3<-\mathrm{X} 2$ & 0,872 & 0,847 & 0,173 & 5,030 & 0,000 \\
$\mathrm{X} 2.4<-\mathrm{X} 2$ & 0,792 & 0,744 & 0,190 & 4,176 & 0,000 \\
$\mathrm{X} 2.5<-\mathrm{X} 2$ & 0,745 & 0,691 & 0,202 & 3,686 & 0,000 \\
$\mathrm{Y} 1.1<-\mathrm{Y}$ & 0,761 & 0,757 & 0,078 & 9,765 & 0,000 \\
$\mathrm{Y} 1.2<-\mathrm{Y}$ & 0,833 & 0,832 & 0,043 & 19,495 & 0,000 \\
$\mathrm{Y} 1.3<-\mathrm{Y}$ & 0,797 & 0,785 & 0,072 & 11,135 & 0,000 \\
$\mathrm{Y} 1.4<-\mathrm{Y}$ & 0,828 & 0,823 & 0,053 & 15,534 & 0,000 \\
Y1.5 <- Y & 0,736 & 0,735 & 0,067 & 10,969 & 0,000 \\
\hline
\end{tabular}

Sumber: Data Primer (2021)

\section{Uji Realibilitas Konstruk (Construct Reliability)}

Reliabilitas konstrak dilakukan dengan cara melihat nilai composite pada konstrak. Nilai batas yang diterima untuk tingkat reliabilitas komposit (pc) adalah 0,7. Berikut tabel pendukung realibilitas konstruk (construct realibity):

Tabel 7. Cronbach's Alpha dan Composite Realibility

\begin{tabular}{lcccc}
\hline Konstrak & $\begin{array}{c}\text { Cronbach's } \\
\text { Alpha }\end{array}$ & Rho_A & $\begin{array}{c}\text { Composite } \\
\text { Realibility }\end{array}$ & $\begin{array}{c}\text { Average } \\
\text { Variance } \\
\text { Extracted } \\
\text { (AVE) }\end{array}$ \\
\hline X1 & 0,847 & 0,866 & 0,887 & 0,612 \\
X2 & 0,870 & 1,004 & 0,901 & 0,646 \\
Y & 0,851 & 0,860 & 0,893 & 0,627 \\
\hline
\end{tabular}

Sumber: Data Primer (2021)

Berdasarkan tabel 7 yaitu tabel realibilitas konstruk (construct reliability).

Diketahui bahwa nilai cronbach's alpha dan composite realibility dari variabel $\mathrm{X} 1, \mathrm{X} 2$ dan $\mathrm{Y}$ memiliki nilai lebih dari 0,7. Dapat dikatakan bahwa nilai cronbach's alpha dan composite reliability reliabel. Sehingga dapat dilanjutkan pada tahap analisis berikutnya. 


\section{Uji Hipotesis (Path Coefficient)}

Dalam penelitian signifikasi pengaruh antar variabel perlu dilakukan prosedur bootstraping. Prosedur bootstrap menggunakan seluruh sampel yang asli untuk melakukan resampling kembali. Berikut hasil uji hipotesis (path coefficient):

Tabel 8. Uji Path Coefficient

\begin{tabular}{lccccc}
\hline & Sampel Asli & $\begin{array}{c}\text { Sampel } \\
\text { Mean }\end{array}$ & $\begin{array}{c}\text { Standar } \\
\text { Deviasi }\end{array}$ & T Statistik & P Value \\
\hline X1 -> Y & 0,336 & 0,367 & 0,105 & 3,209 & 0,001 \\
X2 -> Y & 0,172 & 0,197 & 0,107 & 1,608 & 0,109 \\
\hline
\end{tabular}

Sumber: Data Primer (2021)

Berdasarkan uji path coefficient, maka dapat disimpulkan kualitas produk berpengaruh positif dan signifikan terhadap keputusan konsumen dengan nilai $p$ value sebesar 0,001 atau lebih kecil dari 0,05. Nilai original sample (path coefficient) sebesar 0,336 menunjukkan arah hubungan positif dan harga berpengaruh positif dan tidak signifikan terhadap keputusan konsumen dengan nilai $p$ value 0,109 atau lebih besar dari 0,05. Nilai original sampel (path coefficient) sebesar 0,172 menunjukan arah hubungan positif.

\section{Persamaan Dasar dari Inner Model}

Secara umum rumus persamaan yang digunakan dalam smart PLS sebuah penelitian adalah sebagai berikut :

$$
\mathrm{Y}=\mathrm{aX} 1+\mathrm{bX} 2+\mathrm{e}
$$

Mengenai hasil uji original sampel dari path coefficient, maka dapat dijelaskan bahwa koefisien kualitas produk $(X 1)=0,336$ dan koefisien harga $(X 2)=0,172$. Sehingga diperoleh model persamaan adalah sebagai berikut :

$$
\mathrm{Y}=0,336 \mathrm{X} 1+0,172 \mathrm{X} 2+\mathrm{e}
$$

Koefisien kualitas produk sebesar 0,336 artinya bahwa kualitas produk (X1) memiliki kemampuan untuk menjelaskan keputusan konsumen (Y) sebesar 0,336 atau 33,6\% dan koefisien harga sebesar 0,172 artinya bahwa harga (X2) 
memiliki kemampuan untuk menjelaskan keputusan konsumen (Y) sebesar 0,172 atau $17,2 \%$

\section{Evaluasi Model Struktural}

Evaluasi model dilakukan dengan tiga cara, yaitu dengan melihat nilai hasil uji $f$ square, $R$-square dan model fit sebagai berikut :

1. Hasil Uji f-Square

Uji f digunakan untuk menunjukkan apakah ada pengaruh secara bersama-sama (simultan) dalam menjelaskan informasi terhadap variabel terikat.

Tabel 9. Uji $f$-square

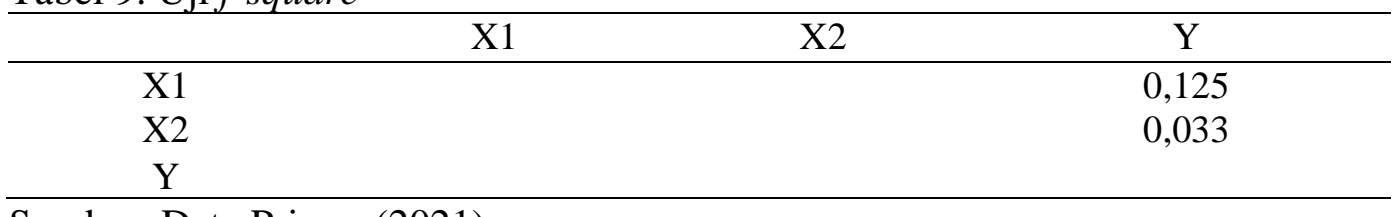

Sumber: Data Primer (2021)

Berdasarkan tabel 9 menunjukkan bahwa pengaruh kualitas produk (X1) terhadap keputusan konsumen (Y) adalah sebesar 0,125 karena nilai $f$-square kualitas produk (X1) terhadap keputusan konsumen (Y) lebih dari 0,02 maka dapat dikatakan memiliki pengaruh sedang terhadap keputusan konsumen (Y). Sedangkan pengaruh harga (X2) terhadap keputusan konsumen (Y) adalah sebesar 0,033 karena lebih dari 0,02 maka dapat dikatakan bahwa harga (X2) memiliki pengaruh sedang terhadap keputusan konsumen (Y).

\section{Hasil Uji R-Square Adjusted}

R-squares untuk setiap variabel laten endogen sebagai kekuatan prediksi dari model struktural. Nilai $R$-squares 0,$75 ; 0,50 ; 0,25$ disimpulkan bahwa model kuat, moderate dan lemah. Semakin tinggi nilai $R$-squares berarti semakin baik model prediksi dari model penelitian yang diajukan atau dilakukan. Sedangkan nilai $R$-square adjusted adalah sebesar 0,155 . Hal ini menunjukkan ada sebesar 15,5\% variabel keputusan konsumen dapat dijelaskan oleh variabel independen kualitas produk dan harga. Maka dapat dikatakan variabel kualitas produk dan harga berpengaruh terhadap keputusan konsumen. 


\section{Analisis Dekriptif Variabel Penelitian Pengaruh Kualitas Produk Terhadap Keputusan Konsumen}

Berdasarkan analisis yang telah dilakukan dapat diperoleh bahwa terdapat pengaruh kualitas produk terhadap keputusan konsumen. Kualitas produk berpengaruh positif dan signifikan terhadap keputusan konsumen dengan nilai $p$ value sebesar 0,001 atau nilai $p$ value lebih kecil dari 0,05. Nilai original sample (path coefficient) sebesar 0,336 menunjukkan arah hubungan positif. Hal ini sejalan dengan penelitian yang dilakukan oleh Pristiana (2013) mengemukakan bahwa kualitas produk memiliki pengaruh terhadap keputusan pembeli. Penelitian yang berbeda yang dilakukan oleh Habibah \& Sumiati (2016) menunjukkan bahwa kualitas produk mempunyai pengaruh secara simultan terhadap keputusan pembelian.

\section{Pengaruh Harga Terhadap Keputusan Konsumen}

Berdasarkan analisis tersebut dapat diperoleh hasil yaitu terdapat pengaruh harga terhadap keputusan konsumen. Harga diketahui tidak signifikan terhadap keputusan konsumen dengan terdapat nilai $p$-value 0,109 atau nilai $p$ value lebih besar dari 0,05. Nilai original sampel (path coefficient) sebesar 0,172 menunjukan arah hubungan yang positif. Penelitian yang dilakukan oleh Harahap \& Hidayat (2017) menunjukkan bahwa harga berpengaruh terhadap keputusan pembelian. Penelitian yang berbeda yang dilakukan oleh Ariyanti \& Darmanto (2019) menunjukkan bahwa hal yang sama yaitu harga secara parsial dan secara simultan memiliki pengaruh terhadap keputusan pembeli.

\section{SIMPULAN}

Berdasarkan hasil analisis mengenai Pengaruh Kualitas Produk dan Harga Terhadap Keputusan Pembelian Sayur Organik di OOF Malang, dapat ditarik kesimpulan antara lain terdapat pengaruh kualitas produk terhadap keputusan konsumen. Kualitas produk berpengaruh positif dan signifikan terhadap keputusan konsumen dengan nilai $p$ value sebesar 0,001 atau lebih kecil dari 
Hariadi, et.al., Pengaruh Kualitas Produk dan Harga Terhadap Keputusan

0,05. Nilai original sample (path coefficient) sebesar 0,336 menunjukkan arah hubungan positif dan terdapat pengaruh harga terhadap keputusan konsumen. Harga tidak signifikan terhadap keputusan konsumen dengan nilai $p$ value 0,109 atau lebih besar dari 0,05. Nilai original sampel (path coefficient) sebesar 0,172 menunjukan arah hubungan positif.

\section{DAFTAR PUSTAKA}

Ariyanti, A., \& Darmanto, R. F. (2019). Kualitas Produk, Harga Dan Ekuitas Merek Berpengaruh Terhadap Keputusan Pembelian Di J'Co Donuts \& Coffee Metropolitan Mal Bekasi. Jurnal Pengembangan Wiraswasta, 21(3), 183. https://doi.org/10.33370/jpw.v21i3.347

Cristo, M., Saerang, D., \& Worang, F. (2017). the Influence of Price, Service Quality, and Physical Environment on Customer Satisfaction. Case Study Markobar Cafe Mando. Jurnal Riset Ekonomi, Manajemen, Bisnis Dan Akuntansi, 5(2), 678-686. https://doi.org/10.35794/emba.v5i2.15962

Davin, J. dan Metta, P., (2016), Pengaruh Kualitas Produk dan Harga Terhadap Keputusan Pembelian Konsumen. Jurnal Entrepreneur dan Entrepreneurship. 5 (7), 27-32. https://doi.org/10.37715/jee.v5i1.384

Devi, L. kurnia intan. (2019). Pengaruh kualitas produk, harga dan promosi terhadap keputusan pembelian pada marketplace Shopee. Skripsi.

Habibah, U. dan Sumiati, (2016), Pengaruh Kualitas Produk dan Harga Terhadap Keputusan Pembelian Produk Kosmetik Wardah di Kota Bangkalan Madura. Jurnal Ekonomi dan Bisnis, 1 (1), 31-48. https://doi.org/10.1234/jeb17.v1i01.635

Harahap, I.A.B. dan Hidayat, W. (2018), Pengaruh Kualitas Produk dan Harga Terhadap Keputusan Pembelian Masker Wajah Mustika Ratu (Studi Kasus pada Konsumen Kec. Tembalang Kota Semarang), Jurnal Ilmu Administrasi Bisnis. 7 (3), 1-9.

Kim, Y.-H., \& Lee, S.-K. (2017). The effects of service quality on satisfaction and behavioral intention in coffee shops. International Journal of Tourism and Hospitality $\quad$ Research, $31 \quad$ (12), https://doi.org/10.21298/ijthr.2017.12.31.12.59

Maaniya, T., Arifin, R., Hufron, M., (2019), Analisis Pengaruh Lokasi, Fasilitas, Kualitas Pelayanan dan Produk Terhadap Keputusan Pembelian Konsumen Pada Sarijan Coffee 2. Jurnal Ilmiah Riset Manajemen. 8 (18), 140-148.

Pertiwi, M. I., Yulianto, E., \& Sunarti. (2016). ( Survei pada Konsumen Baker 's 
King Donuts \& Coffee di MX Mall Malang ). Jurnal Administrasi Bisnis (JAB), 37(1), 179-186.

Pratiwi, N. M. I., \& Yasa, N. N. K. (2019). The Effect Of Store Atmosphere, Social Media Marketing, And Lifestyle On Purchase Decisions On Consumers Of The Alleyway Cafe. European Journal of Management and Marketing Studies, 4(4), 85-100. https://doi.org/10.5281/zenodo.3592913

Pristina, W. (2018). Kualitas dan Harga sebagai Variabel Terpenting pada Keputusan Pembelian Sayuran Organik. Ekspektra : Jurnal Bisnis dan Manajemen, 2 (1), 17-28. https://doi.org/10.25139/ekt.v2i1.675

Putra, P. S. D., Ambarawati, I. G. A. A., \& Yusuf, R. P. (2015). Manajemen Pemasaran Sayur Organik (Studi Kasus pada P4S Eka Setia Lestari di Desa Bangli, Kecamatan Baturiti, Kabupaten Tabanan). E-Journal Agribisnis Dan Agrowisata (Journal of Agribusiness and Agritourism), 4(2), 107-116. Retrieved from https://ojs.unud.ac.id/index.php/JAA/article/vi ew/17393

Sunarto, (2015), Pengaruh Kualitas Produk Terhadap Keputusan Pembelian Pada Toko Kerajinan Kulit Kartika Magetan. Jurnal Ilmiah Ekonomi dan Pembelajarannya. 3

(2), 191-205. http://doi.org/10.25273/equilibrium.v3i2.668 